\title{
Influence of Cold Rolling Process and Chemical Composition on the Mechanical Properties and Corrosion Behavior of Zr-Based Metallic Glasses
}

\author{
Ali Akbarpour 1,*, Daria A. Milkova ${ }^{1}$, Erzhena N. Zanaeva ${ }^{1}$, Mark S. Parkhomenko ${ }^{1}$, Vladimir V. Cheverikin ${ }^{1}$, \\ Alexander Lubenchenko ${ }^{2}$ and Andrey I. Bazlov ${ }^{1,3}$ (D) \\ 1 Department of Physical Metallurgy of Non-Ferrous Metals, National University of Science and Technology \\ "MISiS", 119049 Moscow, Russia; milkovadaria@gmail.com (D.A.M.); zanaeva@misis.ru (E.N.Z.); \\ parkhomenko.m@misis.ru (M.S.P.); cheverikin80@rambler.ru (V.V.C.); bazlov@misis.ru (A.I.B.) \\ 2 Department of General Physics and Nuclear Fusion, National Research University "MPEI", \\ Krasnokazarmennaya 14, 111250 Moscow, Russia; lem_a@mail.ru \\ 3 The Research Laboratory for Mechanics of Advanced Bulk Nanomaterials for Innovative Engineering \\ Applications, St. Petersburg State University, 199034 St. Petersburg, Russia \\ * Correspondence: ali.akbarpour@yahoo.com; Tel.: +7-97-7915-9544
}

check for updates

Citation: Akbarpour, A.; Milkova, D.A.; Zanaeva, E.N.; Parkhomenko, M.S.; Cheverikin, V.V.; Lubenchenko, A.; Bazlov, A.I. Influence of Cold Rolling Process and Chemical Composition on the Mechanical Properties and Corrosion Behavior of Zr-Based Metallic Glasses. Metals 2021, 11, 1514. https://doi.org/ $10.3390 /$ met11101514

Academic Editor: Jordi Sort Viñas

Received: 18 August 2021

Accepted: 20 September 2021

Published: 24 September 2021

Publisher's Note: MDPI stays neutral with regard to jurisdictional claims in published maps and institutional affiliations.

Copyright: (c) 2021 by the authors. Licensee MDPI, Basel, Switzerland. This article is an open access article distributed under the terms and conditions of the Creative Commons Attribution (CC BY) license (https:// creativecommons.org/licenses/by/ $4.0 /)$.
Abstract: Cold rolling (CR) with thickness reduction of $10 \%, 30 \%$, and $50 \%$ was applied to $\mathrm{Zr}_{50} \mathrm{Cu}_{44} \mathrm{Al}_{6}$ and $\mathrm{Zr}_{49.5} \mathrm{Cu}_{44} \mathrm{Al}_{6} \mathrm{Nb}_{0.5}$ metallic glassy ribbon samples. The XRD patterns showed the amorphousness of all samples after casting and CR processes. The SEM images indicated the formation of multiple shear bands (SBs) owing to plastic deformation during CR. However, the addition of $0.5 \mathrm{at} \% \mathrm{Nb}$ to the alloy changed the SBs' density and spacing characteristics. The characterization of free volume changes caused by CR was carried out by measuring the density of Archimedes. The micro-hardness of samples was studied by investigating SBs and free volume during plastic deformation. Alloy softening occurred due to the formation of free volume during CR. X-ray photoelectron spectroscopy (XPS) confirmed the presence of oxides $\mathrm{ZrO}_{2}, \mathrm{CuO}_{\mathrm{x}}$, and $\mathrm{AlO}_{\mathrm{x}}$ on the surface of the ribbons. The anodic polarization curves of the cast and $\mathrm{R} 50$ samples in solutions of $\mathrm{NaCl}$ and $\mathrm{Na}_{2} \mathrm{SO}_{4}(0.5 \mathrm{M})$ were obtained using potentiodynamic polarization measurements. Compared to $\mathrm{CR}$ ribbons, melt-spun ribbons after casting showed better corrosion resistance with lower anodic current densities in $\mathrm{Na}_{2} \mathrm{SO}_{4}$ solution.

Keywords: Zr-based metallic glass; amorphous material; cold rolling; shear band; corrosion; native surface oxide

\section{Introduction}

Metallic glass can be produced in the form of fast solidifying ribbons (usually about 30- $\mathrm{mm}$ thick) and bulk metallic glass (BMG) (thickness $>1 \mathrm{~mm}$ ) [1]. Over the decades, many attempts have been made to develop strategies to overcome failure instability that limits metallic glass to low tensile and compressive ductility or low corrosion resistance. In essence, increasing the number of shear bands through improving the capacity for shear band formation is the main purpose of increasing deformability [2-5]. According to Spaepen's and Argon's research [6,7], plastic flow is the net balance between shear-induced atomic rearrangements that produce free volume (FV) and processes such as diffusion that remove FV. Shear band formation is typically referred to as the results of strain softening due to FV accumulation [3].

To understand the deformation mechanism and to analyze the relationship between the shear band of metallic glass and mechanical properties, it is necessary to understand some parameters of SBs, including the density of SBs, mean distance between SBs, and the intersection between SBs during severe plastic deformation [8]. It has been experimentally confirmed that a decrease in FV (due to structural relaxation) causes the material to become 
brittle. This increases hardness and modulus, reduces shear band formation capacity, and reduces fracture toughness [2].

Free volume is strongly related to the structural and mechanical properties of metallic glasses. For instance, as $\mathrm{FV}$ increases, $\mathrm{Zr}_{56} \mathrm{Co}_{28} \mathrm{Al}_{16} \mathrm{BMG}$ may become less dense and have a higher Poisson's ratio. Higher FV raises the plasticity of $\mathrm{Cu}_{45} \mathrm{Zr}_{48} \mathrm{Al}_{7} \mathrm{BMG}$ [8]. As mentioned above, Spaepen proposed a model where the plastic deformation results from a large amount of the stress-driven creation of free volume by atomic jumps. The local distribution of free volume is thought to control the deformation, and the fertile sites with a higher free volume content can easily accommodate local shear strain that influences the structural and mechanical properties of the metallic glasses [9]. Free volume in the metallic glass is determined by positron annihilation spectroscopy (PAS), density measurements, and differential scanning calorimetry (DSC). Song et al. [10] showed that, for the reason of structural heterogeneities, micro-hardness of the as-cast and as-rolled specimens with a thickness reduction of $2.9 \%$ is $545 \mathrm{HV}$ and $600 \mathrm{HV}$, respectively, after grinding and polishing the surface of the specimens. Meanwhile, Liu et al. [3] found that there was not any change in the surface hardness due to deformation, probably due to low shear band density.

Industrial use of new $\mathrm{ZrCu}$-based $\mathrm{BMG}$ requires addressing the corrosion behavior of the BMG under a variety of environmental conditions. A $\mathrm{ZrCu}$-based BMG corrosion study [11] found that BMG alloys show high corrosion resistance in $\mathrm{H}_{2} \mathrm{SO}_{4}$ solution, but weak corrosion resistance in $3 \% \mathrm{NaCl}$ and $1 \mathrm{~N} \mathrm{HCl}$. Deformation also can affect the corrosion behavior of BMGs by producing SBs, stress fields, or other defects [12]. To know the mechanism of pitting corrosion, it is of researchers' interest to enhance the corrosion resistance of BMG alloys in chloride solutions [11-13].

Various techniques have been found to boost the corrosion resistance of BMGs [11]: (1) changing the composition or structure of the surface by micro-arc oxidation, ion implantation, or other surface treatment techniques; (2) the corrosion resistance of $\mathrm{Zr}$-based alloys is often increased by the reduction of FV; (3) the formation of a glass-matrix composite with the second phase by annealing; and (4) to add elements with strong passivation ability into the base alloy system.

To enhance the industrial application, the corrosion resistance of Zr-based BMG has received a great deal of attention in recent years. Zr-based BMGs have generally been found to exhibit better corrosion resistance than their crystalline counterparts in most aqueous solutions. On the other hand, some valve elements such as $\mathrm{Nb}$ and Ti can increase the corrosion resistance of the base glassy alloys [14].

$\mathrm{Nb}$ is a valve metal and, due to its strong passivation ability, forms a thin barrier surface film [14-17]. It increases the diffusion of $\mathrm{Zr}$ to the surface and suppresses the diffusion of $\mathrm{Cu}$ [18-21]. In the presence of $\mathrm{Nb}$, a significant improvement of pitting resistance was found in the polarization test of a $3 \% \mathrm{NaCl}$ and PBS solution. On the other hand, the addition of $\mathrm{Nb}$ shifted the corrosion potential in the positive direction at $1 \mathrm{~N} \mathrm{HCl}$. Qin et al. [11] reported that $\mathrm{Nb}$ addition to $\mathrm{Cu}-\mathrm{Hf}-\mathrm{Ti}$ BMG could enrich the passivation film not only in $\mathrm{Nb}$ but also in $\mathrm{Hf}$ and Ti while depleting the $\mathrm{Cu}$.

For this work, the $\mathrm{Zr}_{50} \mathrm{Cu}_{44} \mathrm{Al}_{6}$ alloy was selected due to some excellent properties: (1) high glass-forming ability (GFA) up to $25 \mathrm{~mm}$ [11]; (2) excellent mechanical properties of yield strength $\sim 1800 \mathrm{MPa}$ and fracture strength $\sim 2100 \mathrm{MPa}$; (3) good compressive plastic deformation of up to $15 \%$; (4) relatively cheap raw materials (no expensive Pd and Pt elements); (5) it does not contain toxic elements (e.g., Be); and (6) suitable potential biocompatibility [11]. The justification for selecting $\mathrm{Nb}$ as an additional element was as follows: (1) $\mathrm{Nb}$ has a strong passivation ability and (2) refractory metals like $\mathrm{Nb}$ and $\mathrm{Ta}$ can increase the plasticity of Zr-based BMGs by micro-alloying [11].

In this study, the effects of cold rolling deformation and the presence of $\mathrm{Nb}$ on changes in free volume (FV), shear band density and spacing, hardness, and corrosion resistance of $\mathrm{Zr}_{50} \mathrm{Cu}_{44} \mathrm{Al}_{6}$ and $\mathrm{Zr}_{49.5} \mathrm{Cu}_{44} \mathrm{Al}_{6} \mathrm{Nb}_{0.5}$ ribbon samples were investigated. This showed an 
important role of the cold-rolling process and the composition within the basic research and technical application of MGs.

\section{Materials and Methods}

Ingots of the $\mathrm{Zr}_{50} \mathrm{Cu}_{44} \mathrm{Al}_{6}$ (hereafter A1) and $\mathrm{Zr}_{49.5} \mathrm{Cu}_{44} \mathrm{Al}_{6} \mathrm{Nb}_{0.5}$ (hereafter A2) BMGforming alloys were selected for the sake of above mentioned reasons and were produced from high-purity elements ( $\mathrm{Zr}(99.8 \%), \mathrm{Cu}(99.99 \%), \mathrm{Nb}(99.5 \%)$, and $\mathrm{Al}(99.99 \%))$ in an Arc Melter ARC200 (ARCAST Company, Oxford, USA) under a high-purity Ti-gettered Argon atmosphere. Each alloy was turned upside down and remelted at least five times to ensure chemical uniformity. Ribbon samples with a thickness $30 \mu \mathrm{m}$ were prepared using a Vacuum Melt Spinner DX-II (Dexing Magnet Tech. Co., Wuhua, China) with a silica nozzle and a $\mathrm{Cu}$ single roll.

The as-cast ribbon sample was sandwiched and sealed between the outer steel plates at the top and bottom with a thickness of $1.6 \mathrm{~mm}$. A one-dimensional cold rolling process without changing the direction was applied in three thickness reductions $(10 \%, 30 \%$, and $50 \%$ ) by multi-pass gradual reduction $(0.02 \mathrm{~mm}$ per pass on steel plates) until the required degree of thickness reduction was reached. Then, the plates were cut and the exact degree of plastic strain and true plastic strain were determined by measurement of the thickness of the cold-rolled ribbons. The working roll diameter and roll speed were $80 \mathrm{~mm}$ and $13 \mathrm{rpm}$, respectively, (tangential speed of $0.055 \mathrm{~m} / \mathrm{s}$ ).

$\mathrm{X}$-ray diffraction $(\mathrm{XRD})$ with a monochromatic $\mathrm{Cu} \mathrm{K} \alpha$ source was used to determine if crystallization occurred in the as-cast and CR samples. Measurements were performed in a $20^{\circ}$ to $90^{\circ}$ theta-theta configuration. A scanning electron microscope (SEM) was used to monitor the evolution of shear bands during cold rolling. FV changes were determined based on Archimedes density measurements to evaluate the structural changes associated with each amount of deformation. Density measurements were performed after ultrasonic cleaning of the ribbons by ViBRA AF analytical balance (Shinko Denshi Co., Tokyo, Japan) with diethyl phthalate as a working fluid. Each measurement was performed 10 times on each sample to reach a higher accuracy of density measurement. Vickers hardness was tested on the rolling surface of the sample using the Wolfert Wilson 402MVD Micro Hardness Tester 10 gf-2 kgf (WOLPERT Group, Bretzfeld-Schwabbach, Germany). Each reported hardness value was statistically processed from at least 10 indents.

Corrosion tests of the metallic glasses were conducted by potentiodynamic polarization measurements in two different solutions for comparison at $298 \mathrm{~K}$ open to the air. $\mathrm{Na}_{2} \mathrm{SO}_{4}$ and $\mathrm{NaCl}$ electrolytes were prepared as aqueous $0.5 \mathrm{M}$ solutions from chemicals and distilled water. Electrochemical measurements were performed by Professional Onechannel Potentiostats-Galvanostats P-40X (Electrochemical Instruments, Chernogolovka, Russia) in a three-electrode cell using a graphite counter electrode and a standard saturated $\mathrm{Ag} / \mathrm{AgCl}$ reference electrode Potentiodynamic polarization curves were recorded at a scanning range from $-200 \mathrm{mV}$ to $500 \mathrm{mV}$ relative to the open circuit potentials (OCP) and a potential sweep rate of $1 \mathrm{mV} / \mathrm{s}$ after immersing the specimens for approximately $30 \mathrm{~min}$ when OCP became nearly steady.

Surface X-ray photoelectron spectroscopy (XPS) analysis of cast and cold-rolled $\mathrm{Zr}_{50} \mathrm{Cu}_{44} \mathrm{Al}_{6}$ ribbon samples was conducted to investigate the oxidation status of the constituent elements of the oxide layer by the electron-ion spectroscopy module based on the Nano fab 25 (NT-MDT) platform (NT-MDT Co., Moscow, Russia) The analysis chamber used an ultra-high oil-free vacuum of approximately $10^{-6} \mathrm{~Pa}$ and a SPECS XR 50 X-ray source (SPECSGROUP, Berlin, Germany) without a monochromator in an Mg anode (1253.6 eV photons energy). All survey spectra scans were recorded at pass energy of $80 \mathrm{eV}$, and information on the chemical and phase composition of the layers was obtained by the analysis of peaks generated by elastically scattered electrons. The surface XPS spectrum over a wide binding energy region showed an XPS pattern containing $\mathrm{Zr} 3 \mathrm{~d}, \mathrm{Cu} 3 \mathrm{p}, \mathrm{Al}$ $2 \mathrm{p}, \mathrm{O} 1 \mathrm{~s}$, and $\mathrm{C} 1 \mathrm{~s}$. This indicated that the surface oxide film was composed of multiple 
chemical substances. Non-destructive chemical and phase depth profiling of nano-sized films during this study was performed based on Ref. [22].

\section{Results}

\subsection{Structural Evolution by Cold Rolling}

The formation of amorphous phases of the as-cast and cold-rolled samples was confirmed by the X-ray diffraction pattern (Figure 1). XRD patterns represent broad diffraction peaks from $30^{\circ}$ to $50^{\circ} 2 \theta$ angle, demonstrating the amorphousness of all the ribbons after the casting and rolling processes without crystalline phase.
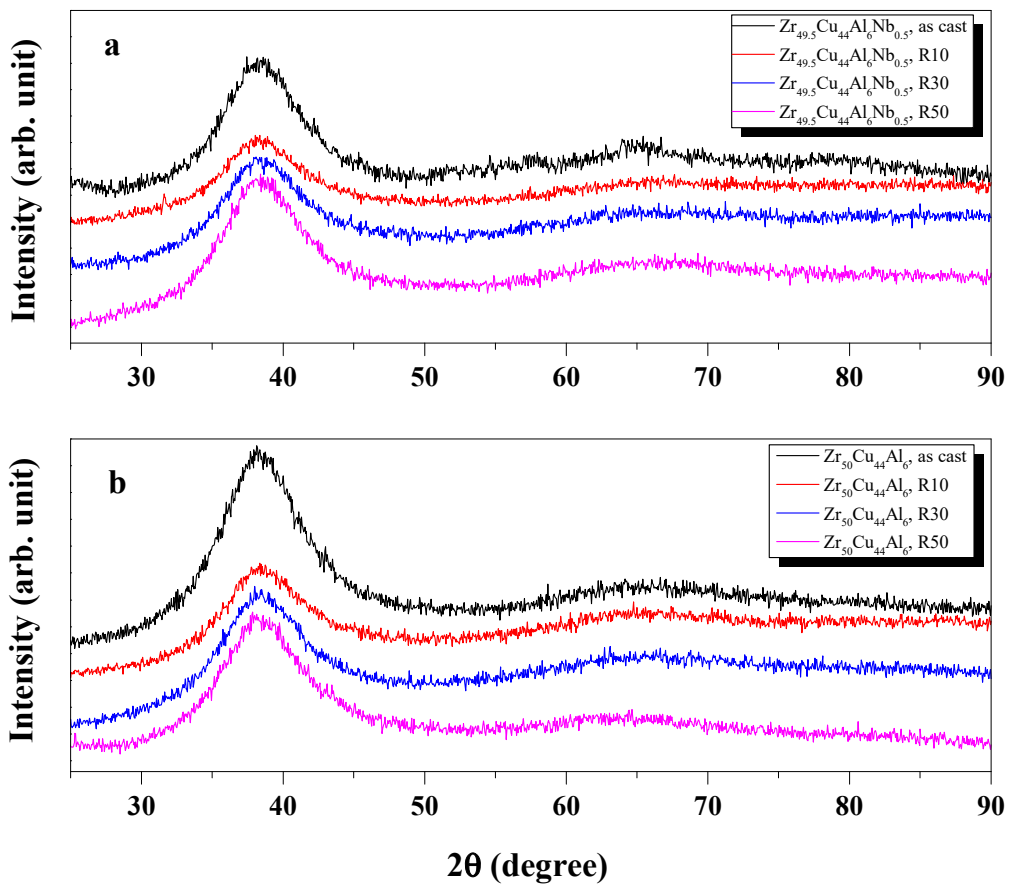

Figure 1. $X R D$ patterns of (a) $\mathrm{Zr}_{49.5} \mathrm{Cu}_{44} \mathrm{Al}_{6} \mathrm{Nb}_{0.5}$ and (b) $\mathrm{Zr}_{50} \mathrm{Cu}_{44} \mathrm{Al}_{6}$ ribbons.

\subsection{Shear Band Formation}

Plastic deformation during rolling caused the formation of multiple shear bands (SBs) [23]. Figure 2 shows the formation of the SBs on RT rolled ribbons with different thickness reductions.

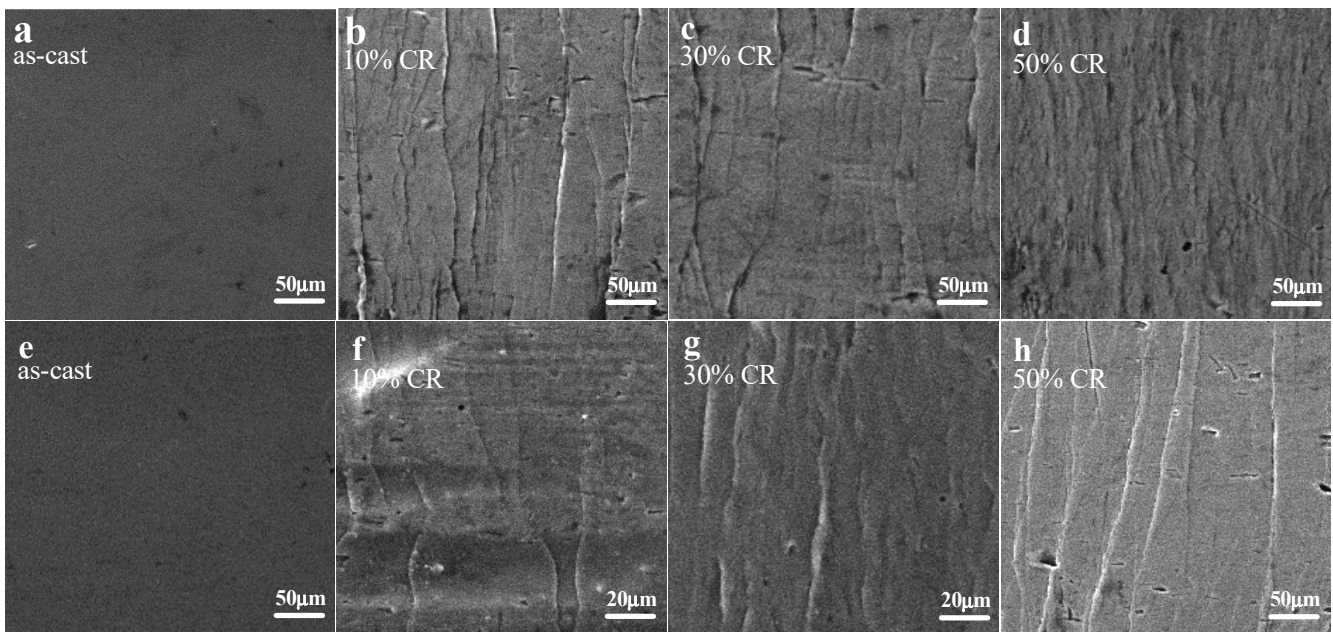

Figure 2. The SEM images for as-cast (a,e) and deformed A1 and A2 ribbons with $10 \%(\mathbf{b}, \mathbf{f}), 30 \%$ $(\mathbf{c}, \mathbf{g})$, and $50 \%(\mathbf{d}, \mathbf{h})$ plastic strains. 
Additionally, the mean shear band spacing $\left(\lambda_{\mathrm{SB}}\right)$ was calculated from at least $35 \mathrm{mi}-$ crographs taken at different positions along the surface of samples at every thickness reduction. The average SB's density $\left(\rho_{\mathrm{SB}}\right)$ was considered as an inverse of the measured average SB's spacing, according to Refs. [2,24]. Figure 3 shows the changes in SBs' density and average SBs' spacing with increasing plastic strain in order to achieve their comparison in two alloys. SBs' density increased with increasing strain [25]. As can be distinguished in Figure 3, the SBs' density trend of all ribbons was on the increase, as opposed to the SBs' spacing.
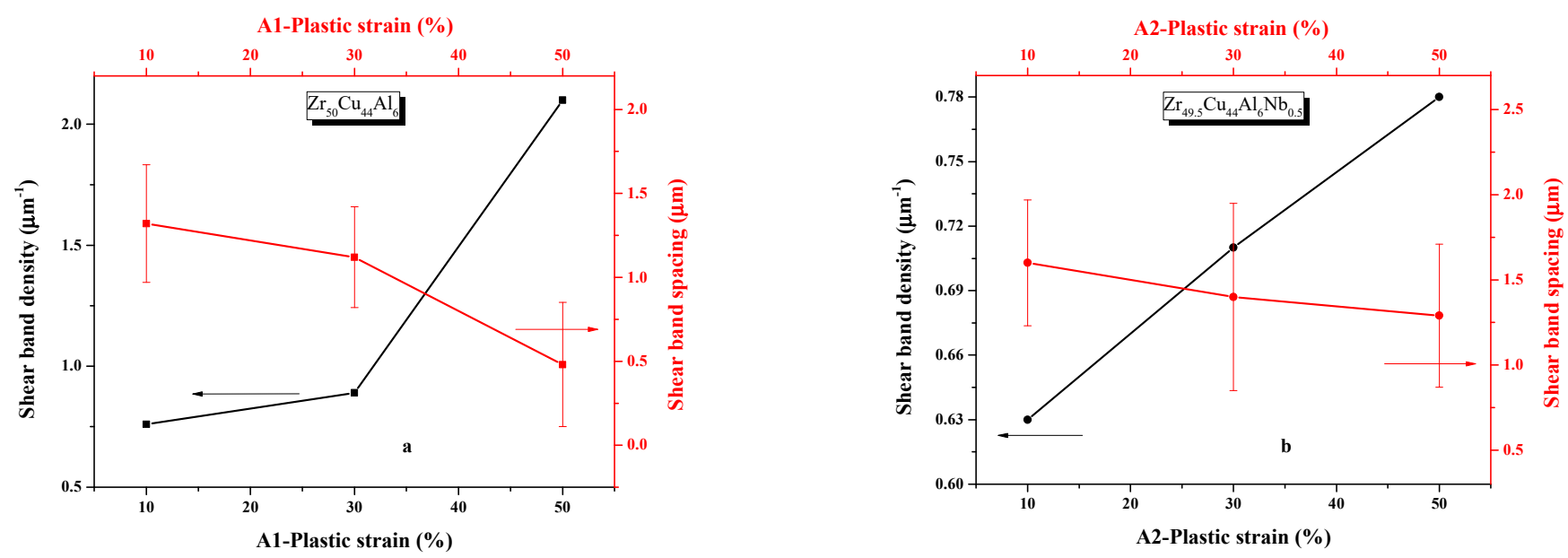

Figure 3. The density and spacing of SBs as a function of the plastic strain of (a) A1 and (b) A2 RT rolled ribbons. Using black lines to present the trend of SBs' density and red lines to present the trend of SBs' spacing.

As the plastic strain of the A1 and A2 alloys increased from $10 \%$ to $50 \%$, the SBs' density increased and the SBs' spacing decreased. The SBs' density and SBs' spacing of A1 increased slightly with plastic strains within the range of $10 \%$ to $30 \%$. However, after a strain of $30 \%$, the change was sharp. However, the addition of $0.5 \mathrm{at} \% \mathrm{Nb}$ changed the characteristic of SBs' density/SBs' spacing, which resulted in a nearly monotonic ascending/descending slope. Moreover, $\mathrm{Nb}$ reduced the maximum and minimum SBs' density of A2 compared to A1 but increased the SBs' spacing.

\subsection{Characterization of the FV by Density Measurements}

The change in material density was considered to be due to the change in FV. Therefore, the change in free volume per atomic volume $\Delta V_{f}$ of the sample $i$ was calculated as [26-28]:

$$
\left(\Delta V_{f}\right)_{i}=\frac{\rho_{0}-\rho_{i}}{\rho_{0}}
$$

where $\rho_{0}$ is the density of the as-cast sample and $\rho_{i}$ is the density of the cold-rolled one. The temperature, pressure, and humidity requirements for measuring density by Archimedes principle are described in the Refs. [29,30]. Figure 4 shows the relation between Archimedes density and FV change in the cast and RT-rolled A1 and A2 ribbons and plastic strain. It is obvious that the densities of $\mathrm{A} 1$ and $\mathrm{A} 2$ over the entire range of plastic strain show a downward trend in both samples on the contrary FV changes.

The density of the A1 and A2 ribbons decreased as the plastic strain increased from $0 \%$ to $50 \%$, whereas the change in FV increased in both samples. However, because of the presence of $\mathrm{Nb}, \mathrm{A} 2$ showed a monotonous up/downslope of FV and density, respectively, together with strain, compared to $\mathrm{A} 1 . \mathrm{Nb}$ reduced the maximum and minimum amount of FV change in A2 compared to A1. Comparing Figures 3 and 4, one is able to see that the SBs' density and FV change increased with plastic strain over the entire range in A1 and $\mathrm{A} 2$, but these values were lower for ribbons A2 than A1. This implies that the lower the SBs' density, the less the FV change. 

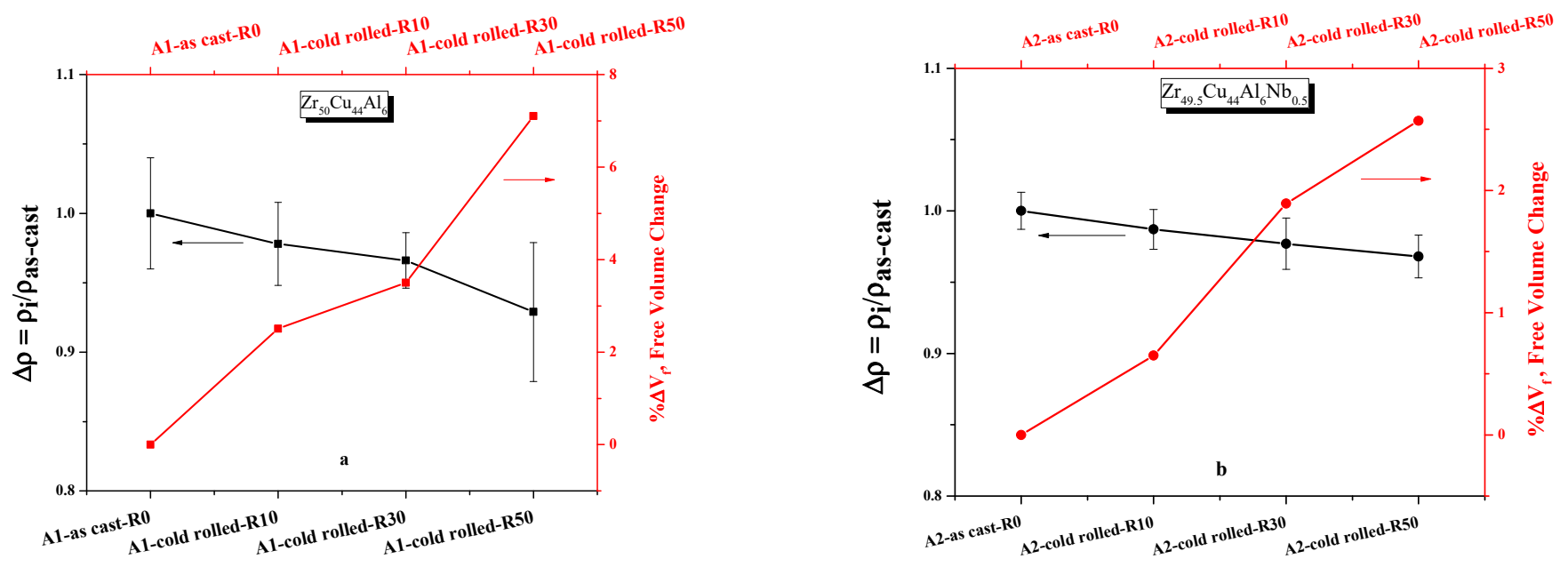

Figure 4. Archimedes density and free volume change induced by cold rolling of (a) A1 and (b) A2 ribbons as a function of plastic strain (R0-R50). Using the black lines to present the trend of density and the red lines to present the trend of FV change.

\subsection{Change in Hardness Due to Cold Rolling}

Figure 5 shows the micro-hardness of the as-cast and rolled pieces plotted against the plastic strain. The Vickers hardness of alloy A1 (black line) decreased from $426 \mathrm{HV}$ (R0) to $362 \mathrm{HV}$ (R50). The Vickers hardness number of alloy A2 (red line) decreased from $433 \mathrm{HV}$ (R0) to a minimum of $377 \mathrm{HV}$ at R50, corresponding to a relative decrease of about $12.9 \%$.

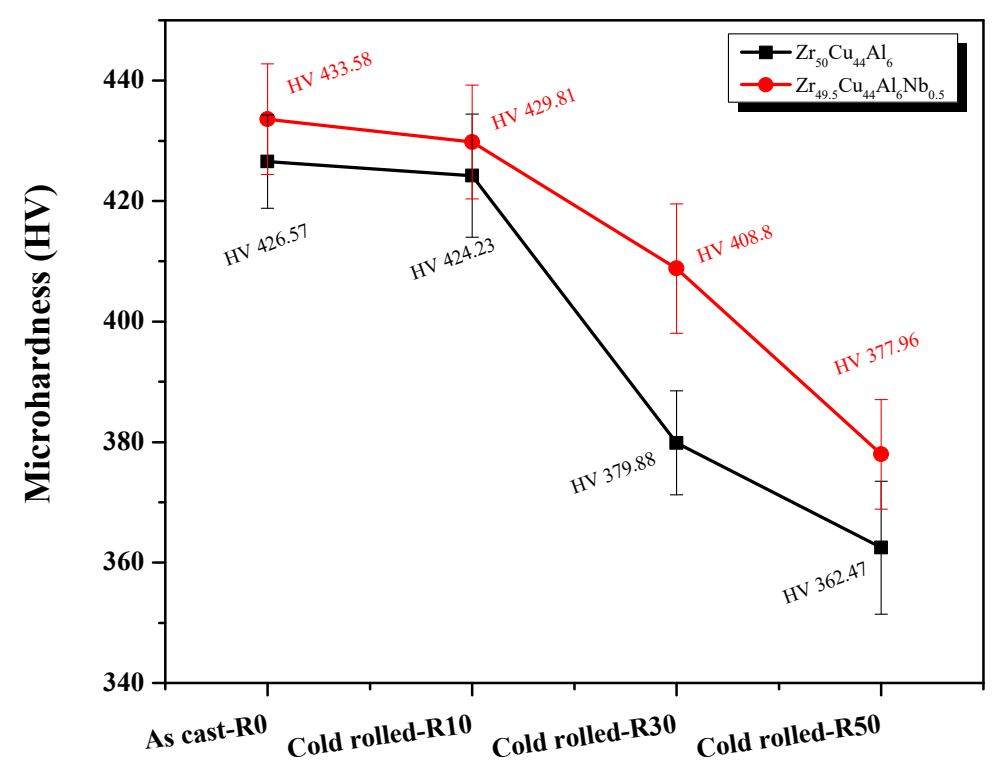

Figure 5. Micro-hardness of samples at different plastic strains.

The hardness difference between R0 and R10 samples was lower than that between the R30 and R50 ones. The main reason for this behavior is the work softening due to the creation of a large amount of free volume. This issue is addressed in the Section 4.

Figure 6 shows the measured hardness as a function of the average SB's density, SB's spacing, and free volume change $\left(\% \Delta V_{f}\right)$ measured in this study. Since the deformation mechanism of the rolled sample was the formation and propagation of SBs, the hardness of the rolled sample was greatly affected by the presence and properties of the shear bands [2]. 

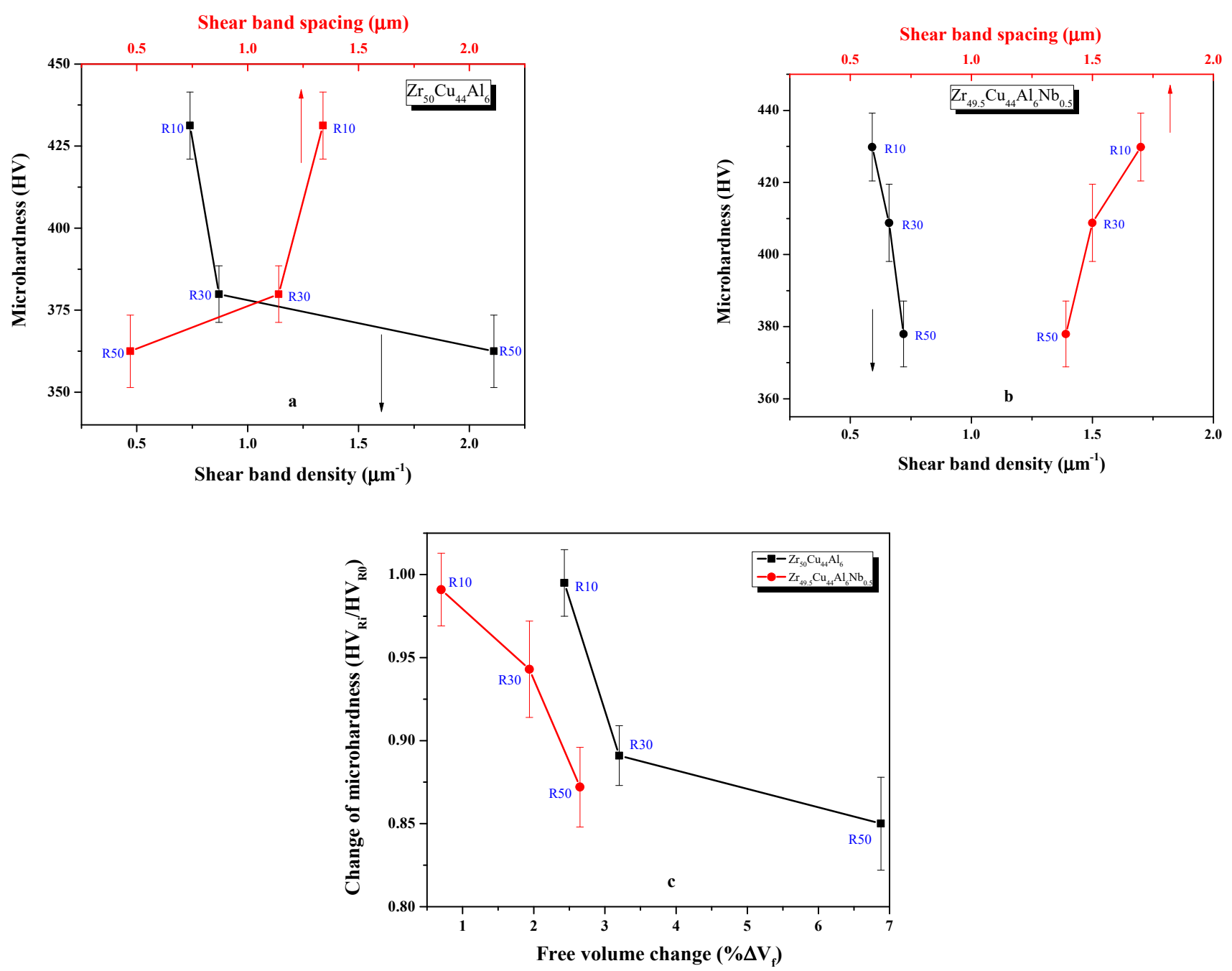

Figure 6. Changes in micro-hardness due to 1-D cold rolling plotted against mean shear band density/shear band spacing and free volume change as a function of $10 \%, 30 \%$, and $50 \%$ plastic strain of (a) A1, (b) A2, and (c) A1 and A2 deformed ribbons.

The measured micro-hardness decreased with increasing SBs' density and plastic deformation in both samples, as opposed to SBs' spacing. As shown in Figure 6a,b, the hardness values of A1 and A2 changed from $431 \mathrm{HV}$ to $362 \mathrm{HV}$ and from $429 \mathrm{HV}$ to $377 \mathrm{HV}$, respectively, as the SBs' density and plastic strain increased. The SBs' spacing showed a decreasing trend.

Figure $6 \mathrm{c}$ indicates the hardness of all ribbons decreased with FV change at different plastic strains. It is clear that when the plastic strain increased to $50 \%$, more FV was introduced in sample A1, which was about 2.5 times that of A2.

\subsection{Corrosion Measurements}

Figure 7 shows the anodic polarization curves of the as-cast and R50 of A1 and A2 alloy samples, which were obtained in $0.5 \mathrm{M} \mathrm{NaCl}$ and $0.5 \mathrm{M} \mathrm{Na}_{2} \mathrm{SO}_{4}$ solutions open to air at $298 \mathrm{~K}$.

As is clear from Figure 7a, the anodic current density of cold-rolled ribbons in $0.5 \mathrm{M}$ $\mathrm{NaCl}$ solution increased rapidly with slight anodic polarization due to general corrosion. However, as-cast samples showed lower anodic current densities, resulting in improved corrosion resistance. Furthermore, the presence of $\mathrm{Nb}$ in the as-cast $\mathrm{A} 2$ alloy was effective in reducing the anodic current density. It is worth noting that cold-rolled alloys showed a slight nobler corrosion potential. Several corrosion-related parameters including corrosion 
potential $\left(\mathrm{E}_{\mathrm{corr}}\right)$ and corrosion current density $\left(\mathrm{i}_{\mathrm{corr}}\right)$ were identified and are summarized in Table 1.
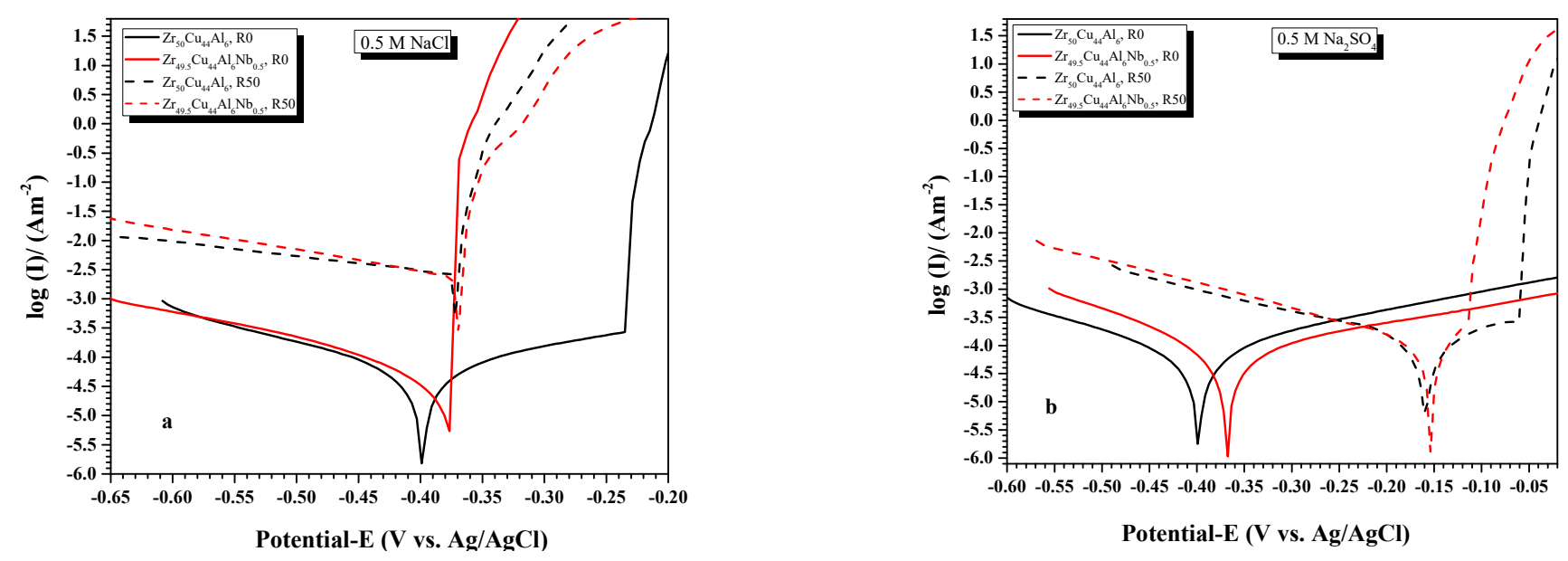

Figure 7. Anodic polarization curves of $\mathrm{R} 0$ and $\mathrm{R} 50$ of $\mathrm{A} 1$ and $\mathrm{A} 2$ ribbons in (a) $0.5 \mathrm{M} \mathrm{NaCl}$ and (b) $0.5 \mathrm{M} \mathrm{Na}_{2} \mathrm{SO}_{4} \mathrm{Solutions}$ at $298 \mathrm{~K}$ open to the air.

Table 1. Corrosion parameters of $\mathrm{A} 1\left(\mathrm{Zr}_{50} \mathrm{Cu}_{44} \mathrm{Al}_{6}\right)$ and $\mathrm{A} 2\left(\mathrm{Zr}_{49.5} \mathrm{Cu}_{44} \mathrm{Al}_{6} \mathrm{Nb}_{0.5}\right)$ ribbons at $\mathrm{R} 0$ and $\mathrm{R} 50$ in $0.5 \mathrm{M} \mathrm{NaCl}$ and $0.5 \mathrm{M} \mathrm{Na}_{2} \mathrm{SO}_{4}$ solutions.

\begin{tabular}{cccc}
\hline Alloys & Plastic Strain, (\%) & $\mathbf{E}_{\text {corr }}, \mathbf{( V )}$ & $\mathbf{i}_{\text {corr, }}\left(\mathbf{A m}^{-\mathbf{2}}\right)$ \\
\hline & & $0.5 \mathrm{M} \mathrm{NaCl}$ & \\
\hline $\mathrm{Zr}_{50} \mathrm{Cu}_{44} \mathrm{Al}_{6}$ & 0 & -0.4 & $2.8 \times 10^{-5}$ \\
$\mathrm{Zr}_{49.5} \mathrm{Cu}_{44} \mathrm{Al}_{6} \mathrm{Nb}_{0.5}$ & 0 & -0.375 & $2.1 \times 10^{-5}$ \\
$\mathrm{Zr}_{50} \mathrm{Cu}_{44} \mathrm{Al}_{6}$ & 50 & -0.375 & $2.0 \times 10^{-3}$ \\
$\mathrm{Zr}_{49.5} \mathrm{Cu}_{44} \mathrm{Al}_{6} \mathrm{Nb}_{0.5}$ & 50 & -0.374 & $1.8 \times 10^{-3}$ \\
\hline & 0 & $0.5 \mathrm{M} \mathrm{Na}_{2} \mathrm{SO}_{4}$ & \\
\hline $\mathrm{Zr}_{50} \mathrm{Cu}_{44} \mathrm{Al}_{6}$ & 0 & -0.397 & $2.6 \times 10^{-5}$ \\
$\mathrm{Zr}_{49.5} \mathrm{Cu}_{44} \mathrm{Al}_{6} \mathrm{Nb}_{0.5}$ & 0 & -0.368 & $1.9 \times 10^{-5}$ \\
$\mathrm{Zr}_{50} \mathrm{Cu}_{44} \mathrm{Al}_{6}$ & 50 & -0.164 & $5.1 \times 10^{-5}$ \\
$\mathrm{Zr}_{49.5} \mathrm{Cu}_{44} \mathrm{Al}_{6} \mathrm{Nb}_{0.5}$ & 50 & -0.152 & $5.0 \times 10^{-5}$ \\
\hline
\end{tabular}

Similar to the curve in Figure 7a, the as-cast samples (R0) of curves in Figure $7 \mathrm{~b}$ in $0.5 \mathrm{M} \mathrm{Na}_{2} \mathrm{SO}_{4}$ solution showed a lower anodic current density, leading to improved corrosion resistance. A2-R0 samples within the presence of $\mathrm{Nb}$ showed low passive current densities. The anodic current density of the cold-rolled samples showed a higher value and an interesting shift of potential to the right, i.e., nobler corrosion potential. Generally, all as-cast ribbons showed lower anodic current densities compared to cold-rolled ribbons. Table 1 shows that the $\mathrm{Na}_{2} \mathrm{SO}_{4}$ solution had a less corrosive effect on these alloys. XPS was performed to explain the shift of the curves to a nobler corrosion potential.

As can be distinguished from the XPS results in Figure 8 and Table 2, the surface XPS spectrum over a wide binding energy region indicated that the surface oxide film formed on the metallic glasses at the corrosive environment was composed of multiple chemical substances. The thickness of these surface films was $5.9 \mathrm{~nm}$ and $6.5 \mathrm{~nm}$ for A1-R0 and A1-R50, respectively. Quantitative analysis of the Zr 3d spectrum demonstrated that the $\mathrm{Zr}$ element content of the native oxide layer of A1-R50 MGs was $7 \mathrm{at} \%$, which was much lower than the as-cast MGs of about 36 at \%. This tendency was the opposite for $\mathrm{Cu}$. In other words, the total content of $\mathrm{Cu}$ elements in the oxide layer increased from 40 at $\%$ at A1-R0 to 66 at\% at R50. The formation of full oxide $\mathrm{Zr}^{4+}$ in the stoichiometric $\mathrm{ZrO}_{2}$ was found in both alloys. 

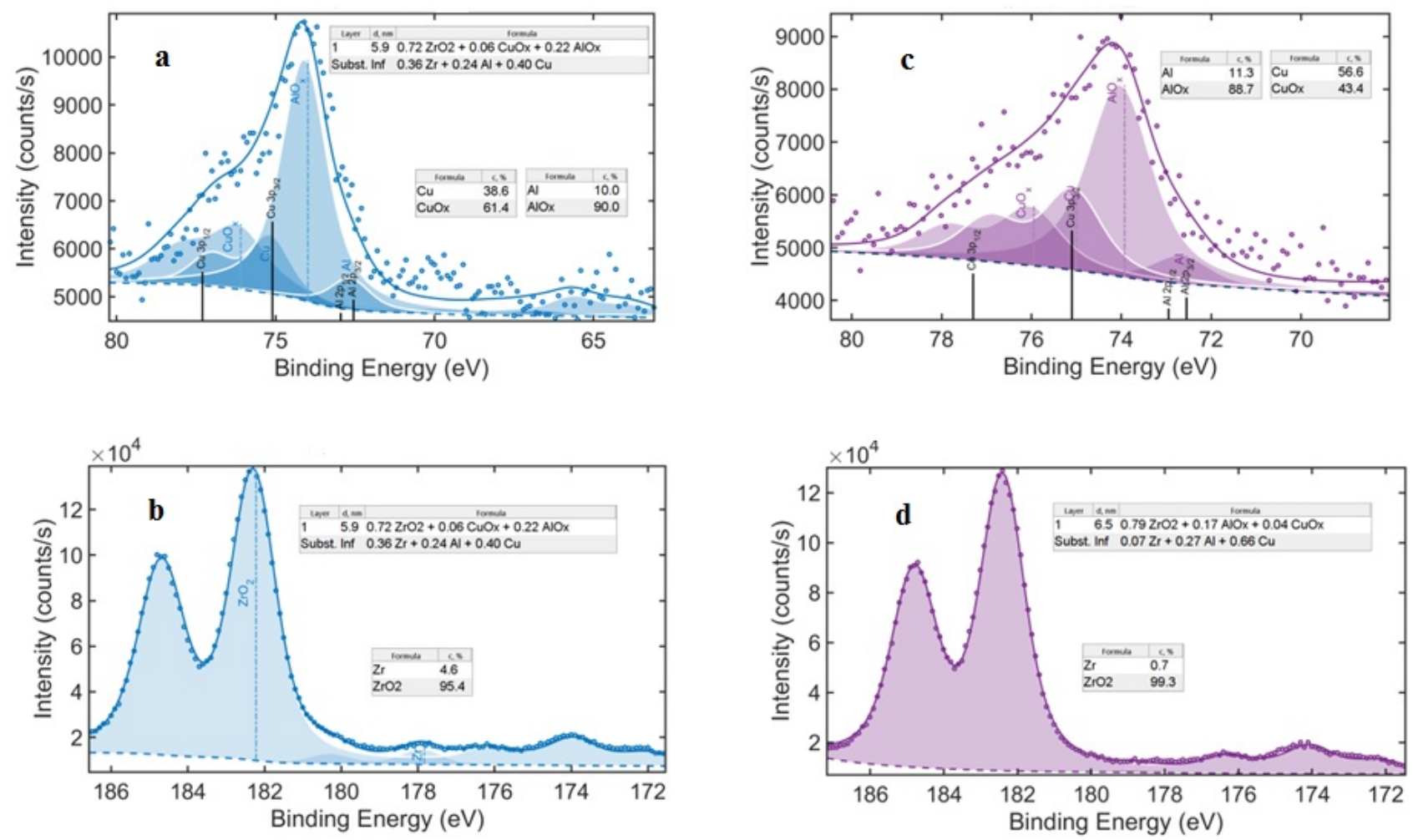

Figure 8. XPS spectra obtained from the surface native oxide layer for $\mathrm{Zr}_{50} \mathrm{Cu}_{44} \mathrm{Al}_{6}$ as-cast ribbon (a) $3 \mathrm{p} \mathrm{Cu}, 2 \mathrm{p} \mathrm{Al}$, and (b) $3 \mathrm{~d} \mathrm{Zr}$ peaks, and for $\mathrm{Zr}_{50} \mathrm{Cu}_{44} \mathrm{Al}_{6} \mathrm{R} 50$-ribbon (c) $3 \mathrm{p} \mathrm{Cu}, 2 \mathrm{p} \mathrm{Al}$, and (d) $3 \mathrm{~d} \mathrm{Zr}$ peaks fitted as indicated. The results indicated that in the oxide layer, $\mathrm{Al}$ mainly formed the $\mathrm{AlO}_{\mathrm{x}}$ compound, $\mathrm{Zr}$ mainly formed the $\mathrm{ZrO} 2 \mathrm{compound}$, and $\mathrm{Cu}$ was partially metallic and partially the $\mathrm{CuO}_{x}$ compound.

Table 2 summarizes the chemical and phase depth profiling of the nano-sized oxide films, formed on the surface of the corroded A1 ribbon with thickness reductions of 0 and 50 .

Table 2. Chemical composition of the native oxide layer on the surface of A1 ribbons, including R0 and R50 in at\% measured by XPS. Ct indicates the total element content of the native oxide layer; $\mathrm{Cp}$ denotes the partial content of different compounds.

\begin{tabular}{|c|c|c|c|c|c|c|}
\hline & \multicolumn{3}{|c|}{$\mathrm{Zr}_{50} \mathrm{Cu}_{44} \mathrm{Al}_{6}$ (As-Cast) } & \multicolumn{3}{|c|}{$\mathrm{Zr}_{50} \mathrm{Cu}_{44} \mathrm{Al}_{6}$ (50\% Thickness Reduction) } \\
\hline & $\begin{array}{l}C^{t} \\
\%\end{array}$ & $\begin{array}{c}\text { Oxide Formula } \\
0.72 \mathrm{ZrO}_{2}+0.06 \mathrm{CuO}_{\mathrm{x}}+0.22 \mathrm{AlO}_{\mathrm{x}}\end{array}$ & $\begin{array}{l}\mathrm{CP}^{\mathrm{p}} \\
\%\end{array}$ & $\begin{array}{l}C^{t} \\
\%\end{array}$ & $\begin{array}{c}\text { Oxide Formula } \\
0.79 \mathrm{ZrO}_{2}+0.04 \mathrm{CuO}_{x}+0.17 \mathrm{AlO}_{\mathrm{x}}\end{array}$ & $\begin{array}{l}\mathrm{CP}^{\mathrm{p}} \\
\%\end{array}$ \\
\hline $\mathrm{Zr}$ & 36 & $\begin{array}{c}\mathrm{ZrO}_{2} \\
\mathrm{Zr}\end{array}$ & $\begin{array}{c}95.4 \\
4.6\end{array}$ & 7 & $\begin{array}{c}\mathrm{ZrO}_{2} \\
\mathrm{Zr}\end{array}$ & $\begin{array}{c}99.3 \\
0.7\end{array}$ \\
\hline $\mathrm{Cu}$ & 40 & $\begin{array}{c}\mathrm{CuO}_{\mathrm{x}} \\
\mathrm{Cu}\end{array}$ & $\begin{array}{l}61.4 \\
38.6\end{array}$ & 66 & $\begin{array}{c}\mathrm{CuO}_{\mathrm{x}} \\
\mathrm{Cu}\end{array}$ & $\begin{array}{l}43.4 \\
56.6\end{array}$ \\
\hline $\mathrm{Al}$ & 24 & $\begin{array}{c}\mathrm{AlO}_{\mathrm{x}} \\
\mathrm{Al}\end{array}$ & $\begin{array}{l}90.0 \\
10.0\end{array}$ & 27 & $\begin{array}{c}\mathrm{AlO}_{\mathrm{x}} \\
\mathrm{Al}\end{array}$ & $\begin{array}{l}88.7 \\
11.3\end{array}$ \\
\hline
\end{tabular}

\section{Discussion}

\subsection{Shear Band Evolution}

To study the formation of the shear bands within the plastic deformation of A1 and A2 ribbon samples, a cold-rolling process was applied to the samples. Shear band evolution during different plastic strains was studied by SEM observations (Figure 2). According to Figure 3, the shear band density increased continuously with the thickness reduction. It is interesting to notice that the shear band densities measured during this study agreed well with the values reported by Liu et al. [3], who performed one-dimensional cold rolling of 
Zr-based BMGs of varied compositions. Additionally, the present results are consistent with the values published by Bei et al. [31], who measured the density of the shear bands as a function of the true plastic strain of Zr-based BMG. In addition to the previously formed shear bands, some secondary fine shear bands with narrow spaces were seen, especially within the deformed A1 sample above R30. When intersections between the primary and secondary shear bands were strengthened, very high plastic strain resulted in strain hardening [8,32]. A few secondary fine shear bands reduced the downward hardness slope of A1 in the range of $30 \%$ to $50 \%$ in comparison to A2. That is why the slope of hardness change of A1 was a smaller amount than A2 from $30 \%$ to $50 \%$.

\subsection{Free Volume Changes}

Since it is not easy to determine the absolute amount of FV, the density change due to structural rearrangement was used to evaluate the difference in FV of the glassy structure. The relevance between density and excess FV stored in the material was first proposed in the Ref. [2] and lately experimentally justified by others [26]. As shown in Figure 4, a decrease in Archimedes density and a continuous increase in FV from R10 to R50 was observed.

Based on the FV model, the formation of SBs always involves the creation of FV. Shear localization of metallic glass was the result of the accumulation of FV in the shear band, which reduced viscosity and ultimately led to strain/thermal softening [23]. Theoretical and experimental results, including the results of atomic simulations, TEM investigations, DSC analysis, and in-situ acoustic emission spectroscopy, showed that the shear bands had more FV compared to the undeformed metallic glass matrix [8]. Therefore, regular studies of FV changes due to plastic strain and quantification of absolute FV content are important to understand the structure and properties of deformed BMG [8]. O. Haruyama et al. [33] measured changes in density and specific volume of as-cast/cold-rolled $\mathrm{Zr}_{55} \mathrm{Cu}_{30} \mathrm{Ni}_{5} \mathrm{Al}_{10}$. As the thickness reduction increased throughout the range, the volume increased. They pointed out that this increase in volume was similar to the increase in the shear band density observed on the lateral surface of cold-rolled specimens. The similarity between the change in the shear band density and the increase in volume showed that the amount of FV generated during cold rolling was closely related to the density of the shear bands in the structure [33]. Therefore, the FV content of the deformed metallic glasses increased with increasing density of the shear band, further affecting the structure and properties of the deformed metallic glasses $[8,25,33]$.

\subsection{Changes in Hardness Due to Plastic Strain}

Figure 5 shows that the hardness of the A1 and A2 samples decreased with plastic strain. The main reason for this behavior was the work-softening due to the creation of a large amount of free volume [34]. As shown in Figure 6, the micro-hardness of the A1 and A2 ribbons decreased with increasing SBs' density. The deformation mechanism of the rolled samples was the formation and propagation of the shear bands. The presence of the shear bands reduced the strength of metallic glasses by creating places for more plastic flow [35]. Spaepen et al. first introduced the FV model to elucidate the deformation mechanism of metallic glass. They pointed out that the generation and annihilation of FV may be competing processes during plastic flow [6]. Because shear bands have more FV than the undeformed matrix, the mechanical properties of BMG are closely associated with the FV content, and, therefore, the hardness of BMG is inversely related to the FV content [6,34]. Tang et al. [36] also noted that the decrease in hardness is mainly due to excessive FV within the shear bands. It is known that increasing FV can reduce the flow stress and hardness of metallic glasses [8]. The increase in FV reduces the barrier to atomic mobility within metallic glasses by providing SBs' nucleation sites. This may result in a reduction in the resistance to further plastic deformation and cause low flow stress of a metallic glass. Therefore, a large amount of FV around the atom is expected to soften the modulus of elasticity of the amorphous alloy by increasing the internal atomic distance 
and reducing the atomic bonding force [5]. In other words, the higher the FV, the higher the plasticity of these BMGs $[10,37]$. The results in Figure 6 are in good agreement with the above considerations.

\subsection{Corrosion Investigation}

The corrosion resistance of metallic glasses is often associated with the formation of passivation films on reactive alloy substrates [38]. Zr, as an example of valve metals, forms a thin, passive, barrier-type layer with low ionic and electrical conductivity. Compared to other metastable (quasi-crystal, nano-crystal) and stable crystalline alloys, Zr-based amorphous alloys show the most effective anodic passivity [38,39]. However, for different Zr-based BMGs, susceptibility to pits caused by chloride and a low re-passivation ability was detected, e.g., in $\mathrm{Zr}_{55} \mathrm{Al}_{10} \mathrm{Cu}_{30} \mathrm{Ni}_{5}, \mathrm{Zr}_{65} \mathrm{Al}_{7.5} \mathrm{Ni}_{10} \mathrm{Cu}_{17.5}, \mathrm{Zr}_{59} \mathrm{Ti}_{3} \mathrm{Cu}_{20} \mathrm{Al}_{10} \mathrm{Ni}_{8}$, and $\mathrm{Zr}_{52} \mathrm{Ti}_{5} \mathrm{Cu}_{17.9} \mathrm{Ni}_{14.6} \mathrm{Al}_{10}$ and for various $\mathrm{Nb}$-containing alloys [39]. The crystalline inclusions of physical defects in cast BMG samples, which act as preferred surface sites with higher energy for chloride attack, are the most probable explanation for the low pitting resistance [39].

Adding $\mathrm{Nb}$ to the glassy alloys increased corrosion potential and decreased anodic current density in both corrosion solutions (Figure 7a,b) and improved corrosion resistance. Within the electrochemical force series, the standard reduction potentials of $\mathrm{Zr}, \mathrm{Cu}$, and $\mathrm{Al}$ were $-1.553 \mathrm{~V},+0.521 \mathrm{~V}$, and $-1.662 \mathrm{~V}$, respectively [40], indicating that $\mathrm{Cu}$ is nobler than $\mathrm{Zr}$ and $\mathrm{Al}$. The pit growth mechanism involved the selective dissolution of $\mathrm{Zr}$ and $\mathrm{Al}$, resulting in local $\mathrm{Cu}$ enrichment within the pit region. Next, $\mathrm{Cu}$ interacted locally with chloride ions to form $\mathrm{CuCl}$, which then hydrolyzed to form $\mathrm{Cu}_{2} \mathrm{O}$. The effect of galvanic coupling with the local presence of $\mathrm{Cu}$-rich species caused local dissolution of the glassy phase, thus leading to the low passivation ability of Zr-based BMG. This could be understood as follows. In the $\mathrm{Zr}-\mathrm{Cu}-\mathrm{Al}$ ternary system, $\mathrm{Zr}, \mathrm{Cu}$, and $\mathrm{Al}$ had a large negative enthalpy of mixing and strong interatomic bonding ability [40]. The enthalpy of mixing of $\mathrm{Nb}-\mathrm{Zr}$, $\mathrm{Nb}-\mathrm{Cu}$, and $\mathrm{Nb}-\mathrm{Al}$ atomic pairs were $+4,+3$, and $-18 \mathrm{~kJ} / \mathrm{mol}[11,41]$, respectively. These indicated that $\mathrm{Nb}$ with a standard reduction potential $-1.1 \mathrm{~V}$ [40] bonded more easily to $\mathrm{Al}$ than $\mathrm{Cu}$ and $\mathrm{Zr}$ and tended to replace $\mathrm{Zr}$ in the $\mathrm{Zr}$-based MGs [42]. $\mathrm{Nb}$ is a valve-metal and forms barrier surface films due to its strong passivity [11,14,16,17], facilitating the diffusion of $\mathrm{Zr}$ onto the surface and suppresses diffusion of $\mathrm{Cu}[19,21]$. As a result, the as-cast A2 ribbon samples exhibited better corrosion resistance.

As mentioned earlier, no phase transformation occurred in the studied specimens during the rolling process. Therefore, the possibility of Nano-crystallization due to deformation or the structure heterogeneity, which led to a decrease in corrosion resistance, was ruled out. So, what are the factors that make the corrosion resistance of samples worse? Deformation-induced FV as a structural defect not only affects mechanical and physical properties but also influences corrosion behavior [43]. Here, density measurement was used to determine the FV content in the ribbons. In this work, by increasing the plastic strain from $10 \%$ to $50 \%$, more FV was applied to the rolled specimens. The entry of FV into the shear bands increased the mean atomic distance, enhanced the atomic mobility and chemical activity, and made it more susceptible to chemical attack. As a result, the shear band was the active site of pitting corrosion, which has been observed in Zr-based systems [43].

To investigate the oxidation states of the constituent elements within the native oxide layer, surface XPS analysis of the as-cast and cold-rolled Zr-based MGs was performed. As shown in Table 2, the Zr content in the native oxide layer A1-R50 MGs was less than A1-R0. This phenomenon is well related to the formation of a $\mathrm{Cu}$-depleted zone at the interface of the oxide-metallic glassy matrix. Cu moved to the oxide, and $\mathrm{Zr}$, as an example of valve metals that has to form a thin passive and barrier-type layer, diffused towards the metallic glass phase. As a result, the corrosion current density ( $\mathrm{i}_{\text {corr }}$ ) of the R50-ribbons increased, and, therefore, the corrosion curves moved up. 
On the opposite hand, Table 2 shows that the presence of $\mathrm{Zr}$ within the native oxide layer of $\mathrm{R} 50 \mathrm{MGs}$ had the highest oxidation state and formed $\mathrm{ZrO}_{2}(99.3 \mathrm{at} \%)$, which was more than $\mathrm{R} 0\left(\mathrm{ZrO}_{2} 95.4 \mathrm{at} \%\right)$. In the authors' best knowledge, this can be the explanation for the interesting shift of corrosion curves of R50-ribbons in Figure 7 to the right, i.e., the more noble corrosion potential. To clarify this phenomenon, during cold rolling, the deformation created many shear band offsets (steps), which added new, excessive, bare surfaces to the whole areas. It seems that they had a high potential to take part in the corrosion process and formation of new protective oxide. According to the XPS results, $\mathrm{ZrO}_{2}$ and $\mathrm{AlO}_{\mathrm{x}}$-enriched oxide film existed on the top surface of the oxidized sample. This may have been due to the preferential oxidation of $\mathrm{Zr}$ and $\mathrm{Al}$. It was obvious that $\mathrm{Zr}$ and $\mathrm{Al}$ had lower electronegativity (1.33 and 1.5, respectively) compared to $\mathrm{Cu}(1.9)$, which implies the higher reactivity of $\mathrm{Al}$ and $\mathrm{Zr}$. Therefore, it was more favorable for $\mathrm{Zr}$ and $\mathrm{Al}$ to form bonds with other elements [44]. Additionally, the heat of formation of $\mathrm{ZrO}_{2}$ and $\mathrm{Al}_{2} \mathrm{O}_{3}$ was -1095 and $-1675 \mathrm{~kJ} / \mathrm{mol}$, respectively, which was much higher than the heat of formation of copper oxide $(-154 \mathrm{~kJ} / \mathrm{mol})$. Therefore, $\mathrm{Zr}$ and $\mathrm{Al}$ had a higher chemical affinity for oxygen than $\mathrm{Cu}$, and the formation of $\mathrm{ZrO}_{2}$ and $\mathrm{Al}_{2} \mathrm{O}_{3}$ was energetically preferable [44,45]. On the other hand, a local increase in free volume and significant shear-induced atomic rearrangements of local structures in cold-rolled samples also may explain the accelerated movement of chemical elements. This enabled other elements such as $\mathrm{Zr}$ and oxygen to easily move in the loose free volume region. These results represent an important advancement within the knowledge of surface oxides and open relation between newly formed, thin oxides and changes in ribbon surface morphology due to the shear bands.

\section{Conclusions}

In this study, the authors investigated the shear band evolution, free volume, microhardness, and corrosion behavior of the as-cast and RT cold-rolled $\mathrm{Zr}_{50} \mathrm{Cu}_{44} \mathrm{Al}_{6}$ and $\mathrm{Zr}_{49.5} \mathrm{Cu}_{44} \mathrm{Al}_{6} \mathrm{Nb}_{0.5} \mathrm{MGs}$ alloys. Plastic deformation during rolling caused the formation of SBs. In the deformed $\mathrm{Zr}_{50} \mathrm{Cu}_{44} \mathrm{Al}_{6}$ sample, in addition to the previously formed shear bands, there were some fine shear bands with narrow spacing, especially when the plastic strain exceeded $30 \%$. This increased the possibility of the shear bands to intersect. On the other hand, 0.5 at $\%$ of $\mathrm{Nb}$ reduced the free volume change in $\mathrm{Zr}_{49.5} \mathrm{Cu}_{44} \mathrm{Al}_{6} \mathrm{Nb}_{0.5}$. The decrease in Archimedes density and, therefore, the continuous increase in FV changes were the results of plastic strain from $10 \%$ to $50 \%$. The number of SBs' density and FV change increased over the whole range of plastic strain of both alloys. On the opposite hand, these values were low within the presence of $\mathrm{Nb}$. The presented results indicate a decrease in hardness because of FV increase at various plastic strains. This implies that the rise in FV reduced the atomic mobility barrier of metallic glasses by providing SBs' nucleation sites. It reduced resistance to further plastic deformation, leading to low flow stress and hardness of MGs. The addition of $\mathrm{Nb}$ to the as-cast glassy alloys showed nobler corrosion potential and lower anodic current density and improved corrosion resistance as well. According to thermodynamics, $\mathrm{Zr}$ has a high chemical affinity for oxygen, and also the formation of $\mathrm{ZrO}_{2}$ is preferable from the viewpoint of energy. Therefore, the formation of new $\mathrm{ZrO}_{2}$ partial oxides on the surfaces due to the offset of shear bands can shift the corrosion curves of ribbons $\mathrm{R} 50$ to the nobler corrosion potential.

Author Contributions: Conceptualization, methodology, investigation, writing—original draft, A.A.; investigation, D.A.M., E.N.Z., M.S.P., V.V.C. and A.L.; writing-review and editing, supervision, A.I.B. All authors have read and agreed to the published version of the manuscript.

Funding: This research was funded by the Ministry of Education and Science of the Russian Federation within the framework of the Increase Competitiveness Programs of MISiS, the Center for Collective Use "Materials Science and Metallurgy" with the financial support of the Russian Federation represented by the Ministry of Education and Science (13.CKP.21.0033) and Andrey Bazlov supported from the RFBR, project number 19-33-60078.

Data Availability Statement: Not applicable. 
Acknowledgments: The authors are sincerely grateful to D.V. Louzguine-Luzgin (WPI Advanced Institute for Materials Research, Tohoku University, Sendai 980-8577, Japan) for assistance in scientific discussion.

Conflicts of Interest: The authors declare no conflict of interest.

\section{References}

1. Vishwanadh, B.; Abraham, G.J.; Neogy, S.; Dutta, R.S.; Dey, G.K. Effect of structural defects, surface irregularities, and quenched-in defects on corrosion of Zr-based metallic glasses. Metall. Mater. Trans. A 2009, 40, 1131-1141. [CrossRef]

2. Stolpe, M.; Kruzic, J.J.; Busch, R. Evolution of shear bands, free volume and hardness during cold rolling of a Zr-based bulk metallic glass. Acta Mater. 2014, 64, 231-240. [CrossRef]

3. Liu, J.W.; Cao, Q.P.; Chen, L.Y.; Wang, X.D.; Jiang, J.Z. Shear band evolution and hardness change in cold-rolled bulk metallic glasses. Acta Mater. 2010, 58, 4827-4840. [CrossRef]

4. Hubek, R.; Hilke, S.; Davani, F.A.; Golkia, M.; Shrivastav, G.P.; Divinski, S.V.; Rösner, H.; Horbach, J.; Wilde, G. Shear bands in monolithic metallic glasses: Experiment, theory, and modeling. Front. Mater. 2010, 7, 1-13. [CrossRef]

5. Tan, J.; Zhang, Y.; Sun, B.A.; Stoica, M.; Li, C.J.; Song, K.K.; Kühn, U.; Pan, F.S.; Eckert, J. Correlation between internal states and plasticity in bulk metallic glass. Appl. Phys. Lett. 2011, 98, 151906. [CrossRef]

6. Spaepen, F. A microscopic mechanism for steady state inhomogeneous flow in metallic glasses. Acta Metall. 1977, 25, 407-415. [CrossRef]

7. Argon, A.S. Plastic deformation in metallic glasses. Acta Metall. 1978, 27, 47-58. [CrossRef]

8. Shi, B.; Xu, Y.; Li, C.; Jia, W.; Li, Z.; Li, J. Evolution of free volume and shear band intersections and its effect on hardness of deformed Zr64.13Cu15.75Ni10.12Al10 bulk metallic glass. J. Alloys Compd. 2016, 669, 167-176. [CrossRef]

9. Brechtl, J.; Xie, X.; Wang, Z.; Qiao, J.; Liaw, P.K. Complexity analysis of serrated flows in a bulk metallic glass under constrained and unconstrained conditions. Mater. Sci. Eng. A 2020, 771, 138585. [CrossRef]

10. Song, K.K.; Pauly, S.; Zhang, Y.; Scudino, S.; Gargarella, P.; Surreddi, K.B.; Kühn, U.; Eckert, J. Significant tensile ductility induced by cold rolling in $\mathrm{Cu}$ 47.5Zr47.5Al5 bulk metallic glass. Intermetallics 2011, 19, 1394-1398. [CrossRef]

11. Nie, X.P.; Xu, X.M.; Jiang, Q.K.; Chen, L.Y.; Xu, Y.; Fang, Y.Z.; Xie, G.Q.; Luo, M.F.; Wu, F.M.; Wang, X.D.; et al. Effect of microalloying of $\mathrm{Nb}$ on corrosion resistance and thermal stability of $\mathrm{ZrCu}$-based bulk metallic glasses. J. Non Cryst. Solids 2009, 355, 203-207. [CrossRef]

12. Nie, X.P.; Cao, Q.P.; Wu, Z.F.; Ma, Y.; Wang, X.D.; Ding, S.Q.; Jiang, J.Z. The pitting corrosion behavior of shear bands in a Zr-based bulk metallic glass. Scr. Mater. 2012, 67, 376-379. [CrossRef]

13. Jiang, W.H.; Jiang, F.; Green, B.A.; Liu, F.X.; Liaw, P.K.; Choo, H.; Qiu, K.Q. Electrochemical corrosion behavior of a Zr-based bulk-metallic glass. Appl. Phys. Lett. 2007, 91, 041904. [CrossRef]

14. Liu, L.; Qiu, C.L.; Zou, H.; Chan, K.C. The effect of the microalloying of Hf on the corrosion behavior of ZrCuNiAl bulk metallic glass. J. Alloys Compd. 2005, 399, 144-148. [CrossRef]

15. Raju, V.R.; Kühn, U.; Wolff, U.; Schneider, F.; Eckert, J.; Reiche, R.; Gebert, A. Corrosion behaviour of Zr-based bulk glass-forming alloys containing $\mathrm{Nb}$ or Ti. Mater. Lett. 2002, 57, 173-177. [CrossRef]

16. Gebert, A.; Gostin, P.F.; Uhlemann, M.; Eckert, J.; Schultz, L. Interactions between mechanically generated defects and corrosion phenomena of Zr-based bulk metallic glasses. Acta Mater. 2012, 60, 2300-2309. [CrossRef]

17. Gebert, A.; Concustell, A.; Greer, A.L.; Schultz, L.; Eckert, J. Effect of shot-peening on the corrosion resistance of a Zr-based bulk metallic glass. Scr. Mater. 2010, 62, 635-638. [CrossRef]

18. Qin, C.; Asami, K.; Zhang, T.; Zhang, W.; Inoue, A. Corrosion behavior of Cu-Zr-Ti-Nb bulk glassy alloys. Mater. Trans. 2003, 44, 749-753. [CrossRef]

19. Mudali, U.K.; Baunack, S.; Eckert, J.; Schultz, L.; Gebert, A. Pitting corrosion of bulk glass-forming zirconium-based alloys. J. Alloys Compd. 2004, 377, 290-297. [CrossRef]

20. Baunack, S.; Mudali, U.K.; Gebert, A. Characterization of oxide layers on amorphous Zr-based alloys by Auger electron spectroscopy with sputter depth profiling. Appl. Surf. Sci. 2005, 252, 162-166. [CrossRef]

21. Qin, C.L.; Zhang, W.; Zhang, Q.S.; Asami, K.; Inoue, A. Electrochemical properties and surface analysis of Cu-Zr-Ag-Al-Nb bulk metallic glasses. J. Alloys Compd. 2009, 483, 317-320. [CrossRef]

22. Lubenchenko, A.V.; Batrakov, A.A.; Pavolotsky, A.B.; Lubenchenko, O.I.; Ivanov, D.A. XPS study of multilayer multicomponent films. Appl. Surf. Sci. 2018, 427, 711-721. [CrossRef]

23. Scudino, S.; Surreddi, K.B.; Eckert, J. Mechanical properties of cold-rolled Zr 60Ti 5Ag 5Cu 12.5Ni 10Al 7.5 metallic glass. Phys. Status Solidi 2010, 207, 1118-1121. [CrossRef]

24. Song, S.X.; Nieh, T.G. Direct measurements of shear band propagation in metallic glasses-An overview. Intermetallics 2011, 19, 1968-1977. [CrossRef]

25. Xu, Y.; Shi, B.; Ma, Z.; Li, J. Evolution of shear bands, free volume, and structure in room temperature rolled Pd40Ni40P20 bulk metallic glass. Mater. Sci. Eng. A 2015, 623, 145-152. [CrossRef]

26. Slipenyuk, A.; Eckert, J. Correlation between enthalpy change and free volume reduction during structural relaxation of Zr55Cu30Al10Ni 5 metallic glass. Scr. Mater. 2004, 50, 39-44. [CrossRef]

27. Suryanarayana, C.; Inoue, A. Bulk Metallic Glasses; Taylor and Francis Group: Boca Raton, FL, USA, 2011; pp. 265-273. 
28. Zhang, Y.; Hahn, H. Characterization of the free volume in a $\mathrm{Zr45.0Cu} \mathrm{39.3Al7.0Ag8.7} \mathrm{bulk} \mathrm{metallic} \mathrm{glass} \mathrm{by} \mathrm{reverse} \mathrm{Monte} \mathrm{Carlo}$ simulation and density measurements. J. Non Cryst. Solids 2011, 357, 1420-1425. [CrossRef]

29. Lee, K.S.; Lee, J.-H.; Eckert, J. On the structural relaxation of bulk metallic glass under warm deformation. Intermetallics 2009, 17, 222-226. [CrossRef]

30. Nowosielski, R.; Januszka, A. Structure and density of Fe 36 Co 36 B 19.2 Si 4.8 Nb 4 bulk glassy alloy. J. Achiev. Mater. Manuf. Eng. 2012, 52, 67-74.

31. Bei, H.; Xie, S.; George, E.P. Softening caused by profuse shear banding in a bulk metallic glass. Phys. Rev. Lett. 2006, 96, 105503. [CrossRef]

32. Gonzaález, S.; Chen, N.; Zhang, Q.S.; Louzguine-Luzgin, D.V.; Perepezko, J.H.; Inoue, A. Effect of shear bands initiated in the pre-yield region on the deformation behaviour of Zr-based metallic glasses. Scr. Mater. 2011, 64, 713-716. [CrossRef]

33. Haruyama, O.; Kisara, K.; Yamashita, A.; Kogure, K.; Yokoyama, Y.; Sugiyama, K. Characterization of free volume in cold-rolled Zr55Cu 30Ni5Al10 bulk metallic glasses. Acta Mater. 2013, 61, 3224-3232. [CrossRef]

34. Zheng, Q.; Chen, D.; Zhang, L.K.; Zhao, X.Y.; Zhang, A.L. Effect of ceramic rolling on the mechanical properties of Zr54Cu38Al8 bulk metallic glass. Mater. Sci. Eng. A 2014, 592, 64-69. [CrossRef]

35. Zhang, P.N.; Li, J.F.; Hu, Y.; Zhou, Y.H. Effect of rolling on the microstructure and mechanical property of Zr52.5Cu17.9Ni14.6Al10Ti5 bulk metallic glass. J. Alloys Compd. 2008, 462, 88-93. [CrossRef]

36. Tang, C.; Li, Y.; Zeng, K. Characterization of mechanical properties of a Zr-based metallic glass by indentation techniques. Mater. Sci. Eng. A 2004, 384, 215-223. [CrossRef]

37. Wang, T.; Wu, Y.; Si, J.; Liu, Y.; Hui, X. Plasticizing and work hardening in phase separated Cu-Zr-Al-Nb bulk metallic glasses by deformation induced nanocrystallization. Mater. Des. 2018, 142, 74-82. [CrossRef]

38. Scully, J.R.; Gebert, A.; Payer, J.H. Corrosion and related mechanical properties of bulk metallic glasses. J. Mater. Res. 2007, 22, 302-313. [CrossRef]

39. Gebert, A.; Gostin, F.; Kühn, U.; Schultz, L. Corrosion of a Zr-based bulk metallic glass with different surface finishing states. ECS Trans. 2009, 16, 1-7. [CrossRef]

40. Guo, S.F.; Zhang, H.J.; Liu, Z.; Chen, W.; Xie, S.F. Corrosion resistances of amorphous and crystalline Zr-based alloys in simulated seawater. Electrochem. Commun. 2012, 24, 39-42. [CrossRef]

41. Cao, G.; Liu, K.; Liu, G.; Zong, H.; Bala, H.; Zhang, B. Improving the glass-forming ability and the plasticity of Zr-Cu-Al bulk metallic glass by addition of $\mathrm{Nb}$. J. Non Cryst. Solids. 2019, 513, 105-110. [CrossRef]

42. Takeuchi, A.; Inoue, A. Classification of bulk metallic glasses by atomic size difference, heat of mixing and period of constituent elements and its application to characterization of the main alloying element. Mater. Trans. 2005, 46, 2817-2829. [CrossRef]

43. Zhou, W.; Hou, J.X.; Sheng, M.Q. Microstructural change and corrosion behavior during rolling of Zr-based bulk metallic glass. Int. J. Electrochem. Sci. 2016, 11, 7163-7172. [CrossRef]

44. Nie, X.P.; Yang, X.H.; Chen, L.Y.; Yeap, K.B.; Zeng, K.Y.; Li, D.; Pan, J.S.; Wang, X.D.; Cao, Q.P.; Ding, S.Q.; et al. The effect of oxidation on the corrosion resistance and mechanical properties of a Zr-based metallic glass. Corros. Sci. 2011, 53, 3557-3565. [CrossRef]

45. Louzguine-Luzgin, D.V.; Chen, C.L.; Lin, L.Y.; Wang, Z.C.; Ketov, S.V.; Miyama, M.J.; Trifonov, A.S.; Lubenchenko, A.V.; Ikuhara, Y. Bulk metallic glassy surface native oxide: Its atomic structure, growth rate and electrical properties. Acta Mater. 2015, 97, 282-290. [CrossRef] 